\title{
Teaching and Learning Tool for Data Communication Course
}

\author{
Rodziah Latih ${ }^{1}$, Rosilah Hassan ${ }^{1} \&$ Zulkarnain Mohd Ali $^{1}$ \\ ${ }^{1}$ School of Computer Science, Faculty of Information Science and Technology, Universiti Kebangsaan Malaysia, \\ Selangor, Malaysia \\ Correspondence: Rodziah Latih, School of Computer Science, Faculty of Information Science and Technology, \\ Universiti Kebangsaan Malaysia, 43600 UKM Bangi, Selangor, Malaysia. Tel: 60-3-8921-6711. E-mail: \\ rodziah@ftsm.ukm.my
}

\author{
Received: September 24, 2012 Accepted: November 7, 2012 Online Published: November 30, 2012 \\ doi:10.5539/ass.v8n16p111 \\ URL: http://dx.doi.org/10.5539/ass.v8n16p111
}

\begin{abstract}
Data Communication is a subject that exposes the students to the overall understanding and knowledge of basic data communication systems. Data Communication is offered to second year students of the Faculty of Information Science and Technology (FTSM), Universiti Kebangsaan Malaysia (UKM). Some of the concepts are difficult to explain using whiteboard but will be easy and interesting if it can be explained using graphics animation and simulation application. Therefore, a teaching and learning tool for this course is needed to help the instructor explain to the student on some of these concepts. This paper describes the used of Wiki as a teaching and learning tool for Data Communication subject.
\end{abstract}

Keywords: data communication course, teaching and learning tool, Wiki, Web 2.0

\section{Introduction}

Data communication subject is offered to second year student in the Faculty of Information Science and Technology (FTSM), Universiti Kebangsaan Malaysia (UKM), with an aim to expose the students to the overall understanding and knowledge in basic data communication systems. The major area of studies include physical interface, transmission medium, data integrity and security, data compression, improving data communication efficiency, data encoding and modulation, architecture and protocol, LAN, internetworking and digital switching system based on the OSI/RM and TCP/IP stacks (Forouzan, 2007). Some of these concepts are difficult to explain on the whiteboard such as framing process and packet transmission. However it will be easy and interesting if it can be explained using graphics animation and simulation application for the concepts (Sun, 2008).

Internet is a technology that provides almost unlimited information very fast and this has made it a great tool to be used in classroom teaching based on e-learning. E-learning is a term which is commonly used referring to learning style that involved all types of technologies. E-learning can improved students' performance as well as provides convenience and flexibility to learners where they are not bound to a specific day/time to physically attend classes. E-learning has been used in all level of education; children, school, higher education. There is also a growing trend to use Web 2.0 technologies as a learning tool like Blogs, Podcasts, and Wikis (Seitzinger, 2006). Even though Wikis and blogs are most commonly known as social software, but because of its several features have made it also suitable for teaching and learning.

This paper describes the used of Wiki as a teaching and learning tool for Data Communication subject. We decided to use Wiki because it supports collaborative learning paradigm; where a group of students work together to complete their task (Parker \& Chao, 2007). This paper is divided into four sections. Initially, the introduction has been explained and in the following section will discuss the background and related works. Section three will discuss the methodology and last section concludes the paper.

\section{Related Works}

In this section we briefly present some of the research literature related to Wiki and Collaborative Learning.

\subsection{Wiki as a Teaching and Learning Tool}

Wiki is one of the Web 2.0 technologies. The term 'wiki' is derived from the Hawaiian phrase, 'wiki-wiki', which means quick. Wiki is a web application that allowing the easy creation and editing using a simplified markup 
language or a WYSIWYG (What You See Is What You Get) text editor. Wiki provide a simple development process which allows user to concentrate on the development of the content rather than the development process. Wiki support collaborative works within and between groups of users. Wiki can be constructed and edited easily with no specialist tools and very little technical expertise. The most famous example of Wiki is Wikipedia, a very wide-ranging on-line encyclopedia that allows anyone to add and edit its entries. Besides collaborative works environment, Wiki also allows user to keep track the history of a document as it is revised. Each time a person makes changes to a wiki page, that revision of the content becomes the current version, and an older version is stored.

Wiki can be used as a teaching and learning tool in several approaches (Bruns \& Humpreys, 2005):

1) as an e-portfolio to keep students' works, projects and assignments.

2) as a support environment for collaborative writing activities among course instructor that teach the same subjects.

3) as a support environment for group project. Wiki provide a simple and basic writing space which allows students to focus on the content of the assignment rather than the presentation of the document. Wiki make writing process visible to instructors therefore encouraging academic honesty and discouraging plagiarism. Course instructors are allowed to monitor the development of the assignment as well as individual contributions.

4) as a discussion forum where students can give their opinion or asking any questions regarding their course subject.

5) to construct course glossary. Each student can be assigned to create definition of identified term and this glossary can be to continual peer review.

6) to construct 'frequently asked questions'. Students can post any questions and course instructor can answer these questions.

7) as a course management system where course instructor can create and maintain course syllabus, reference list, etc. Lessons can have embedded videos, links to supporting websites, and supporting documents.

One of good examples of Wiki as a teaching and learning tool is project Flat Classroom (www.flatclassroomproject2006.wikispaces.com). Flat Classroom is a wiki project between two high school classes from two different countries, International School Dhaka in Bangladesh and Westwood Schools in Camilla, Georgia, United State of America. Students from these two schools work together discussing topics from Thomas Friedmad's book titled "The World is Flat". They used wiki as a tool for project discussion and management.

However, in University of Sheffield (www.shef. ac.uk/teachingcommons/), Wiki is used to connect and create interdisciplinary teaching and learning networks just within the university. While in Oregon State University (www.beavr.com/Main_Page) Wiki is used to provide information for students such as places to eat in the university, university's activities and others.

\subsection{Collaborative Learning Paradigm}

Collaborative learning is a situation where a small group of students interact and share their ideas to improve their understanding, solve their problems cooperatively and complete their common tasks (Cecez-Kecmanovic 2000). Moreover, collaborative learning offers several benefits if compared to individual learning; better performance, better motivation, better grade, high level of achievement, and higher satisfaction. It also encourages the development of critical thinking through discussion, clarification of ideas, and evaluation of others' ideas (Gokhale 1995) provided that the students play an active role in the discussion while course instructor facilitates the groups. There should be no solo teacher and individual students because it becomes an interdependent community with all the joys, tensions and difficulties that attend all communities.

But, how can we encourage the students to take part in the discussion? One proposed solution is to assess both the product and process (Swan, Shen \& Hiltz 2006). The participation can be assessed by counting the number of times the student involved in the discussion. However, study by Brindley, Walti and Blaschke (2009) found that besides group participation assessment, a variety of instructional strategies can improve the quality of group collaboration and increase the student participation. Well planned instructional strategies also can help students to achieve deeper learning and build confidence and skills. These strategies are:

1) Facilitate learner readiness for group work and provide scaffolding to build skills.

2) Establish a healthy balance between structure (clarity of task) and learner autonomy (flexibility of task). 
3) Nurture the establishment of learner relationships and sense of community like informality, familiarity, honesty, openness, heart, passion, dialogue, rapport, empathy, etc.

4) Monitor group activities actively and closely.

5) Make the group task relevant for the learner.

6) Choose tasks that are best performed by a group.

7) Provide sufficient time for the collaborative activities - scheduling, planning, organizing and discussing.

Collaborative learning can be supported by the use of Information and Communication Technologies (ICT) (Cecez-Kecmanovic 2000), (Ludvigsen 2009). Several studies have shown that using ICT in collaborative learning can further enhance the benefits of collaborative learning (Alavi 1994). Tools like VisionQuest (Alavi 1994) and CSILE (Scardamalia \& Bereiter 1994) were developed to support collaborative learning. Web 2.0 tools like wikis and blogs also support for collaborative learning.

\section{Methodology}

The development of Wiki as a learning tool for Data Communication course will be divided into four main stages as shown in Figure 1:

1) The first stage is to study the related works and on how to use wiki system.

2) The second stage is to develop the framework of the tool.

3) The third stage is to identify and develop the content of wiki while the content evaluation of the tool is in stage four.

4) The final stage is to carry out the usability evaluation study of the developed wiki.

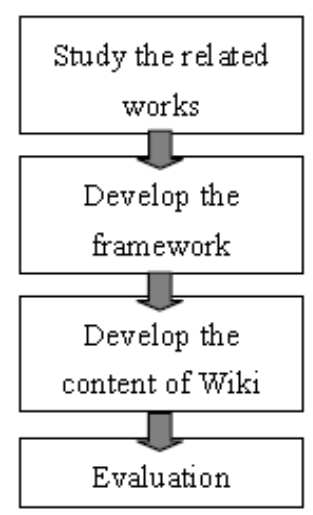

Figure 1. Four stages of development

\section{Future Works and Conclusions}

With the ever increasing topics, notions, concepts, methods and techniques embracing the subject Data Communications it is apparent that more versatile and entertaining forms of teaching and learning are better placed for teachers to expose and express the fundamentals and for students to absorb and learn painlessly. Most dynamic forms of real-time animation and simulation make huge impacts at the perception level during presentation. Putting these together through the use of wiki as a teaching and learning tool not only promotes collaborative work among students and self-learning but it also assist students to pick up more advance Information Communication and Technologies learning outcomes and become literate. Once the basic course tool is developed and evaluated for second year students, we envisage more advance forms of teaching and learning tools for data communication related subjects like computer networking, information sharing, distributed computing and high performance grid computing.

\section{Acknowledgements}

This project was supported by Strategic Action Plan Grant, Universiti Kebangsaan Malaysia (UKM-PTS-0015-2009).

\section{References}

Alavi, M. (1994). Computer-Mediated Collaborative Learning: An Empirical Evaluation. MIS Quarterly, 18(2), 
159-174. http://dx.doi.org/10.2307/249763

Brindley, J. E., Walti, C., \& Blaschke, L. M. (2009). Creating effective collaborative learning groups in an online environment. The International Review of Research in Open and Distance Learning, 10(3).

Bruns, A., \& Humpreys, S. (2005, October 16-18). Wikis in Teaching and Assessment: The M/Cyclopedia Project. International Wiki Symposium. San Diego.

Cecez-Kecmanovic, D., \& Webb, C. (2000). Towards a communicative model of collaborative Web-mediated learning. Australian Journal of Educational Technology, 16(1), 73-85.

Forouzan, A. (2007). Data communications and networking (4th ed.). McGrawHill.

Gokhale, A. A. (1995). Collaborative Learning Enhances Critical Thinking. Journal of Technology Education, $7(1)$.

Ludvigsen, S. R., \& Morch, A. I. (2009). Computer-Supported Collaborative Learning: Basic Concepts, Multiple Perspectives, and Emerging Trends. The International Encyclopedia of Education (3rd ed.). Elsevier.

Parker, K. R., \& Chao, J. T. (2007). Wiki as a Teaching Tool, Interdisciplinary. Journal of Knowledge and Learning Objects, 3.

Scardamalia, M., \& Bereiter, C. (1994). Computer Support for Knowledge-Building Communities. The Journal of the Learning Science, 3, 265-283. http://dx.doi.org/10.1207/s15327809j1s0303_3

Seitzinger, J. (2006). Be Constructive: Blogs, Podcasts, and Wikis as Constructivist Learning Tools. Learning Solution e-Magazine. Retrieved November, 2012, from http://www.elearningguide.com/pdf/2/073106DES.pdf

Sun, P.-C., Tsai, R. J., Finger, G., \& Chen, Y.-Y. (2008). What Drives a Successful e-Learning? An Empirical Investigation of the Critical Factors Influencing Learner Satisfaction. Computer \& Education, 50, 1183-1202. http://dx.doi.org/10.1016/j.compedu.2006.11.007

Swan, K., Shen, J., \& Hiltz, S. R. (2006). Assessment and Collaboration in Online Learning. Journal of Asynchronous Learning Networks, 10(1), 45-62. 